\title{
A extensão das ideias conservadoras-liberalizantes do processo constituinte por meio de juristas do trabalho: uma agenda de pesquisa
}

Karen Artur e Ligia Barros de Freitas

\section{Karen Artur}

Professora de Direito da Universidade Federal de Juiz de Fora, Doutora em Ciência Política pela pela Universidade Federal de São Carlos (UFSCar) com doutorado sanduíche na Northwestern University, e Mestre em Ciências Sociais pela Universidade Federal de São Carlos (UFSCar).

Email: karenartur2014@gmail.com

ORCID: https://orcid.org/0000-0003-3568-912X

\section{Ligia Barros de Freitas}

Professora de Direito da Universidade Estadual de Minas Gerais, Doutora em Ciência Política pela Universidade Federal de São Carlos (Ufscar) com período sanduíche em Centre de Recherches Politiques de Sciences PO, França-Paris e Mestre em Ciências Sociais pela Universidade Federal de São Carlos (Ufscar). Email: ligiadefreitas@ig.com.br ORCID: https://orcid.org/0000-0002-4285-4376

\section{Resumo}

O presente artigo analisa a permeabilidade do posicionamento conservador-liberal na constitucionalização de direitos do trabalho e, posteriormente, a sua proeminência no período pós-constituinte, principalmente na Reforma Trabalhista. Para tanto, são analisados os embates travados na Assembleia Nacional Constituinte de 1987-88 e, em relação ao período mais recente, as ações no STF sobre a reforma trabalhista, bem como as ideias centrais de membros do Grupo de Altos Estudos do Trabalho (GAET), instituído pelo governo de Jair Messias Bolsonaro, para aprofundar essa reforma. As disputas, com a prevalência do posicionamento conservador-liberal, estão ressignificando o arcabouço jurídico, para favorecer o mercado e confrontar os direitos fundamentais.

Palavras-chave: Constituição; Reforma Trabalhista; GAET; STF; ideias conservadoras-liberais

\section{Abstract}

This article analyzes the permeability of the conservative-liberal position in the constitutionalization of labor rights and, subsequently, its prominence in the postconstituent period, mainly in the Labor Reform. In order to achieve this end, the conflicts at the 1987-88 National Constituent Assembly are analyzed and, in relation to the most recent period, the actions in the Supreme Court on labor reform, as well as the central ideas of members of the Group of High Studies of Labor (GAET), instituted by the government of Jair Messias Bolsonaro, to deepen this reform. The disputes, 
with the prevalence of conservative-liberal positioning, are giving new meaning to the legal framework in order to favor the market and to confront fundamental rights.

Keywords: Constitution; Labor Reform; GAET; STF; conservative-liberal ideas

\section{Resumen}

Este artículo analiza la permeabilidad de la posición conservadora-liberal en la constitucionalización de los derechos laborales y, posteriormente, su importancia en el período posterior a la constitución, principalmente en la Reforma Laboral. Con este fin, se analizan los enfrentamientos en la Asamblea Nacional Constituyente de 1987-88 y, en relación con el período más reciente, las acciones en la Corte Suprema sobre la reforma laboral, así como las ideas centrales de los miembros del Grupo de Altos Estudios Laborales (GAET), instituido por el gobierno de Jair Messias Bolsonaro, para profundizar esta reforma. Las disputas, con la prevalencia del posicionamiento conservador-liberal, están dando un nuevo significado al marco legal para favorecer el mercado y confrontar los derechos fundamentales.

Palabras clave: Constitución; Reforma laboral; GAET; STF; ideas conservadorasliberales 


\section{Introdução}

Este artigo traz um panorama sobre os prolongamentos do posicionamento conservador-liberal na área da regulação do trabalho, desde o processo legislativo que culminou com a aprovação da Constituição Federal de 1987/1988, até períodos mais recentes. O objetivo é analisar como esse posicionamento ganha maior proeminência, durante o período pós-constituinte, na área do direito do trabalho, com as sucessivas tentativas de mitigação de direitos constitucionalmente previstos, por meio de alteração da legislação infraconstitucional, desaguando na reforma trabalhista de 2017 e no efetivo desmonte do sistema de proteção social do trabalhador. De fato, como acrescenta Paixão (2018), desde o impeachment da Presidente da República Dilma Rousseff, temos vivido um aprofundamento do processo desconstituinte, cujo principal objetivo é a desconfiguração do quadro de direitos fundamentais, o núcleo da Constituição de 1988. Nesse sentido, operando no nível infraconstitucional, mas visando a afrontar esses direitos, encontra-se a reforma trabalhista, instituída pela Lei $13.467 / 2017$.

Outros autores relatam como chegamos ao momento atual, de reformas com caráter nitidamente nefasto aos direitos sociais, esticando na linha do tempo, fatos pretéritos mais longínquos. Nesse sentido, segundo Lynch (2020), as reformas ocorreram como resultado da abertura à manifestação dos conservadores, com seus discursos antissistema, em resposta a fatores externos, como os ataques terroristas e o colapso pelas crises financeiras sucessivas de 2008 , e no plano interno, com a saturação do modelo de governabilidade, escândalos políticos de corrupção e a extensão da permanência dos governos social-democratas, embora legitimamente empossados. Em 2015, formou-se uma vasta coalizão oposicionista, de liberais e conservadores, promovendo a reforma do sistema através do Judiciário, derrubando 0 governo social-democrata, na linha do que o autor denominou de judiciarismo. Cardoso (2020), no mesmo sentido, destaca o golpe parlamentar contra Dilma Rousseff como o ponto alto de "uma sequência assustadora de menoscabro dos poderes republicanos, particularmente o Poder Judiciário, em relação à Constituição de $1988^{\prime \prime}$.

As questões relativas à proteção do trabalhador são analisadas levando em consideração a proposta de uma visão ampliada do espaço público e da comunidade de intérpretes da Constituição, de modo a promover a cidadania social no processo de deliberação pública (VIANNA, 1999). Contudo, também é observado o avanço de posicionamentos conservadores nos poderes institucionais - Executivo, Legislativo e Judiciário - para impor restrições a visões mais protetivas dos direitos trabalhistas.

Assim, o artigo percorre as disputas de sentido na área da regulação do trabalho, destacando o período da redemocratização, especialmente nos embates travados na Assembleia Nacional Constituinte (ANC) de 1987-88 e no período mais recente, com as alterações infraconstitucionais e as interpretações judiciais do Supremo Tribunal Federal (STF), no contexto da reforma trabalhista de 2017, que ressignificou o arcabouço jurídico protetivo ao trabalhador, tornando-o mais flexível e de acordo com a visão conservadora- liberal.

Apesar dos constrangimentos, a Assembleia Nacional Constituinte de 1987-88 conseguiu instituir garantias relevantes ao trabalhador, de modo que forças conservadoras não conseguiram se sobrepor, muito embora o texto constitucional final 
tenha sofrido alguns retrocessos, se comparado com os projetos advindos das fases anteriores.

O mesmo não ocorreu no período pós-constituinte, especialmente quando, anteriormente às recentes mudanças no mundo do trabalho decorrentes da Reforma Trabalhista (Lei 13.467/2017), entidades empresariais buscaram rupturas, fora do processo legislativo, com o uso de procedimentos judiciais junto ao STF, obtendo como resposta interpretações desfavoráveis ao trabalhador, a exemplo da ampliação da terceirização para todas as atividades (ARTUR, GRILLO, 2020).

Ainda mais recentemente, apesar da profundidade da reforma trabalhista, 0 governo Bolsonaro estabeleceu o Grupo de Altos Estudos do Trabalho (GAET) com o propósito de "avaliar o mercado de trabalho brasileiro sob a ótica da modernização das relações trabalhistas e matérias correlatas", e que, com discursos questionáveis, valorizou novamente a maior flexibilização das leis do trabalho em prol do mercado e da suposta criação de novos empregos ${ }^{1}$.

Para analisar especialmente como a legislação protetiva do trabalho sofreu significativa alteração, decorrente do progressivo avanço do discurso conservadorliberal nas instituições dos três poderes, utilizamos a abordagem institucionalista, que possibilita acompanhar o redirecionamento do direito do trabalho, em conformidade com o ambiente político, econômico e institucional. Segundo a vertente do institucionalismo histórico, as instituições distribuem poder, influência e são responsáveis pela própria definição dos interesses políticos dos grupos (ROTHSTHEIN, 1998; HALL, TAYLOR, 2003).

Koerner (2013) identificou a existência de relações entre governo e elites jurídicas em busca de um certo regime governamental. Nesse sentido, é possível notar uma atuação estratégica de alguns juristas do trabalho com posições institucionais de destaque para avançar suas visões sobre os papéis que a Justiça do Trabalho deve ter, em conformidade com os ambientes políticos e econômicos (SILVA, 2008; PESSANHA, 2010; FREITAS, 2011; ARTUR, 2012), ou seja, no caso deste trabalho, de juristas defensores das reformas trabalhistas já ocorridas, apoiadores da continuação e aprofundamento dessas reformas e defensores de um discurso baseado na eficiência do mercado.

O institucionalismo histórico, segundo Hall e Taylor (2003, p. 200), focou-se no modo "como as instituições repartem o poder de maneira desigual entre grupos sociais", dividindo-os entre perdedores e ganhadores nas disputas. No caso do direito do trabalho, fica muito clara a disputa entre grupos que defendem um viés protecionista do trabalhador e grupos que priorizam a liberdade do mercado. Esses grupos sempre disputaram esses sentidos, mas, desde a reforma trabalhista de 2017, diante de um novo ambiente político e institucional, os juristas afinados com uma ordem conservadora-liberalizante ganharam destaque no processo legislativo da reforma e utilizaram-se de suas posições institucionais dentro e fora do Judiciário para legitimá-la, bem como às suas visões sobre o papel do direito e das instituições do trabalho.

A coalizão de grupos que sustentam o governo Bolsonaro, sem dúvida, tem suas especificidades, as quais foram recentemente delineadas por Lynch (2020). Embora representem uma novidade, especialmente pelo grau máximo de destruição das instituições do trabalho, pode-se afirmar, porém, que tais disputas por mudanças 
institucionais nessa área dão continuidade a um processo que sempre ocorreu, seja durante ou após a Constituinte de $1988^{2}$.

Trabalhamos com a hipótese, portanto, de que, desde a conformação da referida coalizão, estamos vivenciando um ambiente político que tende a reforçar ideias de total ruptura com o viés protecionista do direito do trabalho, inclusive com suas regras constitucionais, optando pela negação dos conflitos que permeiam as relações de trabalho e afirmando a busca por mudanças institucionais que garantam a chamada segurança jurídica propalada pela reforma trabalhista, dirigida apenas aos interesses do mercado.

Desse modo, esses discursos dos atuais "vencedores" na disputa, podem ser acompanhados não apenas dentro do campo jurídico, mas também em sua relação com os demais poderes e com os atores sociais, sendo também direcionados pelas e para as entidades patronais. Com isso, as demandas por abertura a uma real participação política nos debates sobre tais mudanças não são bem aceitas, já que podem possibilitar o questionamento das "melhores" visões conservadorashistoricamente construídas- sobre o que o país precisa (CHALOUB, 2020).

Ao usar a expressão conservador-liberal, este artigo refere-se ao hibridismo do conservadorismo culturalista com o liberalismo individualista, que Lynch denomina de "liberalismo de mercado", "eis que crente no mercado como supremo regulador da vida coletiva" (LYNCH, 2020, p. 22). Para o autor, o liberalismo tem a liberdade como valor supremo, sendo o conservadorismo uma ideologia que se guia pelo caráter extrahumano da ordem social, de modo a impedir as tentativas de mudança. Outra característica do conservadorismo é que ele é adaptável plasticamente ao adversário, ou seja, a argumentação do outro é absorvida e inoculada com valores contrários.

No caso específico das relações de trabalho, o discurso conservador pauta-se na mão invisível do mercado para regulamentar a força de trabalho e no argumento de desregulação da legislação trabalhista. Na Constituinte, o grupo conservador foi formado principalmente pelo grande empresariado paulista, agindo através da Federação das Indústrias do Estado de São Paulo (Fiesp) e por constituintes mais à direita no espectro político, como Afif Domingos (Partido Liberal/ São Paulo). A partir da época da Reforma Trabalhista, representado pela Fiesp e Confederação Nacional da Industria (CNI), as instituições financeiras, por políticos mais à direita e da ultra-direita no espectro político, com o reforço da grande mídia e de juristas inseridos tanto na Justiça do trabalho, como no STF.

O presente texto, além da introdução e das considerações finais, está dividido em três partes. Na primeira, trazemos concepções críticas do constitucionalismo brasileiro, a partir da interpretação de Cittadino (1999; 2002) e Vianna et al (1999; 2002), apontando as dificuldades de adoção de uma interpretação fundada num constitucionalismo comunitário. Na segunda parte, são abordadas as visões conservadoras sobre o arcabouço jurídico trabalhista e as investidas do Poder Executivo e Legislativo, por meio de um discurso sobre a impossibilidade de implementação dessa proteção social frente à necessidade de criação de empregos e de crescimento econômico. Na terceira parte, o foco volta-se para o STF, com suas decisões corroborando o discurso de efetividade econômica e de necessidade da modernização trabalhista.

\section{Visões sobre o Constitucionalismo}


A emergência dos movimentos de defesa dos direitos humanos, as lutas contra o regime autoritário, a reconquista do direito de participação política, a efetiva participação de setores organizados no processo constituinte, iniciativas das quais decorreu a Constituição de 1988 em contraponto à nossa democracia de baixa intensidade, tudo isso provocou a incorporação da linguagem de direitos no país.

Refletindo sobre esses desdobramentos, as contribuições do debate entre o liberalismo, o comunitarismo e a teoria de Habermas para a filosofia constitucional tornaram-se objetos de estudo na Ciência Política brasileira. Se muitos autores contribuíram para o debate, os pioneiros Cittadino (1999) e Vianna et al(1999), interessam a este artigo por exporem a marca do constitucionalismo comunitário no processo constituinte de $1987 / 88$.

O constitucionalismo comunitário defende a ampliação do espaço público com uma visão da liberdade positiva que prioriza um projeto comum de uma determinada sociedade, de modo que os direitos fundamentais devem promover uma cidadania ativa no processo de deliberação pública (Cittadino, 1999:18). A partir dessa visão de constitucionalismo e da luta pela democratização do país, a comunidade jurídica é chamada a efetivar a proposta do alargamento da comunidade de intérpretes da Constituição (Cittadino, 1999: 19), cujo determinante institucional estaria na ampliação do rol de legitimados a propor as ações de controle de constitucionalidade, da capacidade de controle das omissões do poder público e dos demais dispositivos que promovem o papel dos cidadãos enquanto autores do direito.

No mesmo sentido, Vianna et al (1999) demonstram como a "a política se judicializa a fim de viabilizar o encontro da comunidade com os seus propósitos, declarados formalmente na Constituição"(Vianna et al, 1999, p. 40). Para os autores, a percepção dos constituintes de que, na época da transição, a sociedade brasileira, apesar de ter propósitos de garantir direitos fundamentais, não possuía mentalidade cívica e uma cultura política democrática para o desenvolvimento de uma cidadania ativa, levou-os a constituir os instrumentos que garantiriam, no futuro, a proteção destes direitos fundamentais. Caberia às gerações futuras garantir a efetividade da vontade geral expressa na Constituição, através do uso dos mecanismos colocados à disposição pelo próprio texto constitucional.

Para Cittadino (1999), a concretização da Constituição depende não apenas do Judiciário, cuja função é estabelecer uma aproximação entre o direito e a realidade histórica, mas, fundamentalmente, de formas democráticas de participação comunitária. Ao definir uma série de institutos processuais asseguradores dos direitos fundamentais, o constitucionalismo democrático, comprometido com a dignidade humana e com o processo de participação jurídico-política da comunidade, reclama prestações positivas do Estado no conjunto dos direitos fundamentais civis, políticos e sociais.

No entanto, por meio da análise das obras de Habermas e Dworkin, Cittadino (1999, p. 203) questiona a visão substantiva de democracia, que tem base em sociedades com confiança nas tradições constitucionais. Em contextos históricos nos quais se faz necessário um distanciamento reflexivo em relação às tradições, o compromisso entre o Estado de Direito e a democracia não se fundamenta em conteúdos substantivos, mas em procedimentos que asseguram a formação democrática da vontade política de uma comunidade ética. 
A partir dessa visão habermasiana, Cittadino (1999, p. 230) também tece uma crítica ao constitucionalismo comunitário brasileiro, segundo o qual a força legitimadora da formação democrática da vontade derivaria da convergência de concepções éticas assentadas em valores compartilhados. A autora, apoiando-se na análise de Wanderley Guilherme dos Santos (1994), constata que a história constitucional brasileira é marcada por rupturas e violações aos direitos fundamentais, além da sociedade apresentar profundas divisões sociais reguladas por um contrato hobbesiano de sociabilidade que informa ações oportunistas de alteração do pacto constitucional. Dessa forma, em países que não possuem forte republicanismo cívico ou uma comunidade de princípios que compartilha tradições e valores históricos e culturais, "a visão substantiva da democracia constitucional dever ser substituída por uma visão procedimental da democracia constitucional" (CITTADINO, 2002, p. 21).

Reafirmando a ética procedimental habermasiana, Cittadino (1999, p. 231) defende que a constitucionalização do sistema de direitos deve ser resultado de um procedimento democrático, o que pressupõe um consenso constituído a partir de processos intersubjetivos de formação da vontade política popular ancorados no conflito e na diferença, o que teria uma maior justificação. A autora aponta para a necessidade de uma relação entre a força do direito e a força da política, trazidas à tona pela mobilização popular e pela institucionalização do Judiciário como assegurador dos mecanismos e normas constitucionais, sem prescindir da participação e controle populares.

Para Vianna e Burgos (2002), a procedimentalização do direito abriu espaço para uma "soberania complexa", comum nas sociedades modernas, na qual tem-se uma pluralidade de formas para exercer a soberania, através dos processos da democracia deliberativa, participativa e das organizações não-governamentais, significando que, ao lado da cidadania formal, com os ritos eleitorais, há a cidadania social. Dessa forma, através da cidadania política, o homem comum participa dos procedimentos democráticos, que levam à produção da lei, e através da cidadania social, tem ele mesmo acesso à procedimentalização na aplicação da lei.

A Constituição Federal de 1988, segundo Cittadino (2002), expressa a recusa ao constitucionalismo liberal, marcado pela defesa ao individualismo racional, conferindo prioridade aos valores de igualdade e dignidade humana, através do constitucionalismo societário e comunitário.

Na seara trabalhista, contudo, a procedimentalização do direito, através dos mecanismos de controle constitucional, e os ambientes da agenda legislativa, estão sendo utilizados para estimular interpretações judiciais e discursos a favor de leis trabalhistas que desregulam o mercado e atacam os direitos fundamentais e as instituições públicas do trabalho.

\section{Da normatização do trabalho na Constituinte à formação do GAET: a disputa pela proeminência do pensamento conservador nos Poderes Legislativo e Executivo.}

Antes mesmo da Constituinte, a disputa entre uma visão mais protetiva ao trabalhador e ideias conservadoras-liberais já havia sido travada na Comissão Afonso Arinos. Embora suas contribuições não tenham sido formalmente utilizadas como texto base da Constituição de 1988, ela influenciou os trabalhos ocorridos na Assembleia 
Nacional Constituinte (SALGADO, 2005; FREITAS, 2012). Conforme Bastos (2018), houve uma forte pressão da sociedade civil sobre os trabalhos da mencionada Comissão, acabando por produzir um projeto no qual prevaleceram as matérias tidas como progressistas, subvertendo a dinâmica anteriormente esperada para a comissão. Se, inicialmente, a comissão foi vista como elitista e com grande probabilidade de produzir um texto retrógrado, após o projeto pronto, passa a ser duramente criticada pelos conservadores, empresariado, grande mídia e militares.

A Constituição de 1988 elevou, ao status constitucional, direitos previstos na CLT e expandiu os direitos sociais e do trabalho. Contudo, o próprio processo constituinte mostra que a Carta nasceu marcada pelo embate entre as ideias liberalizantes, que ganhariam ainda mais força na década de 90 , e as demandas pela expansão desses direitos.

Especificamente, na Assembleia Nacional Constituinte de 1987-1988, os embates de posicionamento se acirraram na Comissão de Sistematização, em decorrência da alteração do Regimento Interno, após a formação do "Centrão", onde prevaleciam as forças conservadoras. Se antes das alterações no Regimento interno, provocadas pelo Centrão, o ônus maior para ver aprovadas as matérias trabalhistas segundo seus interesses, era da ala mais conservadora, a situação se inverteu a partir do momento em que entrou em vigor o novo regimento (DINIZ; NORONHA, 2008; FREITAS, 2012).

Junto aos constituintes, dois atores representaram as visões diferentes sobre os direitos trabalhistas. No lado progressista, com ideais protetivos ao trabalhador, o Departamento Intersindical de Apoio Parlamentar (DIAP) teve o importante papel de canalizar as posições unânimes dentro do movimento sindical, entidade que tinha conquistado, desde o início dos anos 80, grande relevância no processo da redemocratização, capaz de influenciar as fases iniciais do processo constituinte, principalmente na Subcomissão dos Direitos dos Trabalhadores e Servidores Públicos e na Comissão Social. No lado conservador, a partir da Comissão de Sistematização, foi o empresariado, representado pela Fiesp, que atuou principalmente quanto à estabilidade no emprego.

Nesse sentido, os direitos trabalhistas que haviam sido conquistados na subcomissão e comissão, como a jornada de trabalho de 40 horas semanais, hora noturna de 45 minutos, proibição de hora extraordinária e de intermediação de mãode-obra, foram modificados, segundo os interesses da ala mais conservadora da ANC.

Aliás, um dos temas no qual esse embate mais se evidenciou foi na questão da jornada de trabalho, com os discursos contrários ao estabelecimento da mesma em 40 horas, o que poderia afugentar o capital. COSTA (2013) também nota esse conflito, trazendo a visão de Roberto Campos, para o qual o futuro do país estaria na liberalização do mercado, e contrapondo-a à visão de Florestan Fernandes, para o qual o futuro do país estava na construção democrática sustentada pelos direitos sociais.

Desde então, vivemos sob o constante resgaste dessas ideias liberalizantes, num movimento perene de busca do retrocesso na pauta de direitos do trabalho. É recorrente a afirmação por parte da ala conservadora sobre a necessidade de facilitação do ambiente de negócios, com mitigação da legislação trabalhista, a fim de que haja inserção dos trabalhadores no mercado formal. Tal inserção, contudo, desconsidera a qualidade desses trabalhos em termos da agenda de direitos. Com isso, quando há uma janela de oportunidade política, essa agenda volta a ser acionada para 
lembrar que a solução estaria em mais reformas nos direitos do trabalho, com discursos desligados da face cidadã da Constituição.

No governo Fernando Henrique Cardoso (FHC) foram implementadas mudanças, tornando o mercado de trabalho brasileiro altamente flexível, mas, ainda assim, não houve a descaracterização do modelo legislado (NORONHA, 2000; NORONHA, DE NEGRI, ARTUR, 2006). Foi neste governo que o discurso de flexibilização dos direitos do trabalho ganhou força, principalmente frente às novas exigências competitivas em uma economia globalizada. Embora não tenha havido uma reforma ampla, conforme Krein e Oliveira (2003), adotou-se uma série de iniciativas pontuais de alteração da legislação trabalhista, recorrendo principalmente a medidas provisórias, portarias e decretos, que tentavam desregulamentar os direitos sociais, principalmente quanto às condições de contratação e demissão. Inúmeras foram as alterações flexibilizando as normas do trabalho existentes, dentre elas, a desindexação salarial; a aprovação da participação dos trabalhadores nos lucros e resultados das empresas, desvinculada da remuneração; a denúncia da Convenção 158, da Organização Internacional do Trabalho (OIT), que protege os trabalhadores do setor privado contra dispensas imotivadas; a criação do contrato por prazo determinado, com redução de contribuições sociais e do FGTS; e a introdução de banco de horas, a estipulação do trabalho em tempo parcial e a possibilidade de suspensão de contrato de trabalho.

Por sua vez, o governo de Luiz Inácio Lula da Silva acenou com a tentativa de trazer maior proteção à dispensa injustificada, quando enviou ao Congresso Nacional proposta de ratificação da convenção 158 da OIT, que já tinha sido denunciada, em 1996, mas houve reações contrárias. Da mesma forma, embora tenha havido alguns consensos para uma reforma sindical, obtidos no Fórum Nacional do Trabalho, promovido pelo governo Lula, não houve sucesso em avançá-la por via do processo legislativo (OLIVEIRA, 2018). Ademais, segundo Artur (2012), no mencionado governo, o Executivo deixou de ter papel proeminente na produção de leis flexibilizadoras, passando a ter atuação importante na fiscalização do trabalho escravo e infantil e na elaboração de leis para o combate à informalidade.

Apesar dos impactos positivos do aumento na formalização, das políticas sociais e das negociações coletivas ocorridas no governo Luiz Inácio Lula da Silva (BALTAR, 2010), com as crises política e econômica advindas desde o governo Dilma Rousseff, os debates sobre os efeitos da legislação sobre o mercado voltaram a ser acionados, opondo custos e direitos, numa espécie de eterno enquadramento, que afasta o aprofundamento em torno das políticas públicas de desenvolvimento e do papel dos trabalhadores nessas políticas.

A reforma trabalhista de 2017 avançou na oferta de padrões contratuais atípicos da CLT, ampliando as esferas de negociação com centralidade no indivíduo e na empresa, apesar do discurso de fortalecimento da negociação coletiva, da qual se pretende-resultados que sejam favoráveis apenas às empresas. Isso foi feito sem discussão pública efetiva e com forte disseminação do discurso que afasta a necessidade da proteção trabalhista (KREIN, OLIVEIRA, FILGUEIRAS, 2019).

Segundo o discurso do empresariado, o elevado custo do trabalho e burocracia trabalhista eram responsáveis pelo descompasso entre o crescimento da produtividade e dos salários. Com a bandeira de "modernização" das relações de trabalho, a reforma avançou, com o discurso de que a legislação trabalhista engessava o mercado de 
trabalho, impondo limites à livre contratação dos trabalhadores. A autonomia da vontade coletiva, com a saída do Estado na tutela das relações de trabalho, seria a forma de assegurar a segurança jurídica e de impedir excessiva ingerência dos tribunais trabalhistas nas relações de trabalho (CESIT, 2017).

Muitos dos argumentos utilizados pelo relator do projeto da Reforma Trabalhista, o deputado Rogério Marinho (PSDB/RN), são encontrados nas formulações das entidades patronais como, por exemplo, nos textos da Confederação Nacional da Indústria (CNI): 101 Propostas para Modernização Trabalhista, 2012; da Agenda Legislativa da Indústria, 2014; de Caminhos da Modernização Trabalhista, 2016; e da CNA (Proposta da Bancada de Empregadores, 2016; Balanço 2016 e Perspectivas 2017) (CESIT, 2017).

Durante a tramitação do projeto da reforma, em jornais de grande circulação, também houve ataques à CLT e à Justiça do Trabalho por parte de representantes das instituições financeiras, a exemplo da reportagem "A importância da reforma trabalhista" 3 , de autoria do banqueiro Roberto Setubal, dono do maior banco privado do país. Outros bancos elaboraram documentos de apoio à aprovação do projeto de reforma trabalhista, mencionando os custos da legislação, como o documento do Banco Santander, intitulado "Reforma Trabalhista: Informalidade e Insegurança Jurídica" (MARGATO, MORAN, 2017).

Para a Reforma Trabalhista, com curto e excepcional lapso de tempo entre a propositura e sua aprovação, não se abriram debates para os atores interessados no mundo do trabalho, prevalecendo as ideias conservadoras-liberalizantes, apoiadas pela grande mídia e pelo empresariado, representados pela CNI e Fiesp. Entre outras modificações, a lei ampliou o conceito de trabalhador autônomo; criou novas formas de extinção do vínculo empregatício, facilitando as dispensas, ao diminuir a multa sobre o Fundo de Garantia por Tempo de Serviço (FGTS) e verbas rescisórias, no comum acordo; facilitou a dispensa com a retirada da obrigatoriedade de homologação sindical; instituiu contrato de trabalho intermitente e ampliou a terceirização para as atividades-fim; reduziu a proteção dos trabalhadores em relação à insalubridade; retirou a natureza salarial de parcelas antes assim consideradas. No âmbito do direito coletivo do trabalho, inverteu a lógica até então predominante, passando a negociação coletiva a prevalecer sobre o legislado. Além disso, nas estruturas das instituições do trabalho, promoveu reformas dificultando o acesso do trabalhador à Justiça do trabalho, com a obrigatoriedade de pagamentos de custas e despesas processuais, mesmo quando beneficiado com a Justiça Gratuita, e, em relação os sindicatos, retirou abruptamente a obrigatoriedade das contribuições sindicais.

O governo de Jair Messias Bolsonaro, com o propósito de avançar mais nas reformas trabalhistas flexibilizantes, estabeleceu o Grupo de Altos Estudos do Trabalho (GAET). Chama à atenção o fato das relações interinstitucionais entre o ministro do TST, Ives Gandra Martins Filho, que se tornou o porta voz das mudanças realizadas na reforma trabalhista, e o atual governo, por meio do GAET, não serem realmente abertas à sociedade. $O$ relatório de suas atividades não foi publicado, mas seus membros são opinantes ativos sobre temas trabalhistas, em eventos ou na mídia.

O GAET é responsável por elaborar propostas para o aprofundamento da reforma trabalhista, sendo composto por quatro Grupos de Estudos Temáticos (GET), a saber: GET de Direito do Trabalho e Segurança Jurídica; GET de Trabalho e Previdência; GET de Liberdade Sindical e GET de Economia do Trabalho. Para analisar 
a alteração das leis do trabalho, o presente artigo focou principalmente no GET de Direito do Trabalho e Segurança Jurídica, composto por: Ives Gandra Martins Filho Ministro do TST e coordenador; Ana Luiza Fischer - Juíza, TRT/MG e coordenadora adjunta; Alexandre Agra Belmonte - Ministro do TST; Douglas Alencar Rodrigues Ministro do TST; Bento Herculano Duarte Neto - Desembargador. do TRT/RN; João Bosco Pinto Lara - Desembargador TRT/MG; Sônia Mascaro Nascimento Desembargadora do TRT/SP, André Araújo Molina - Juiz, TRT/MT; Rodrigo Dias da Fonseca - Juiz, TRT/GO; José Eduardo Duarte Saad - Advogado; Antônio das Dores Pereira da Silva - Assessor legislativo.

Destaca-se, primeiramente, que este eixo do grupo é formado por atores que participaram da formulação da reforma trabalhista de 2017. Em segundo lugar, quando procuramos eventos disponíveis online dos quais esses atores participaram, encontramos o "Seminário Visões da Modernização Trabalhista", promovido pela CNI, ocorrido em novembro de $2017^{4}$. O evento ganha destaque por ter reunido Ives Gandra Martins Filho, Ana Fischer, João Bosco Pinto Lara. Em terceiro lugar, é evidente a inexistência de atores vinculados aos sindicatos dos trabalhadores ou mesmo a associações de juristas que apresentaram críticas à reforma, por outros meios ${ }^{5}$.

Observamos que o argumento que une tais participantes é o da necessidade de segurança jurídica, a qual aparece sob três facetas. A primeira é de crítica "ao posicionamento ideológico" dos juristas que se manifestaram contra a reforma. A segunda é contrária às decisões da Justiça do Trabalho que não teriam parâmetros em lei e que causariam dificuldades para as empresas. A terceira refere-se à legitimidade de mudanças que possibilitem o afastamento dos conflitos da Justiça do Trabalho.

Neste trabalho, nos centraremos nos argumentos do ministro Ives Gandra Martins Filho, árduo defensor da reforma, que participou da Casa Civil no governo Fernando Henrique Cardoso, foi presidente do TST e que, agora, lidera o GAET. Além do evento promovido pela CNI, acima citado, o ministro participou, em novembro de 2019, do "I Congresso Brasileiro de Segurança Jurídica", promovido pelo Instituto Brasileiro de Segurança Jurídica (IBSEJUR) e Escola Superior do Ministério Público do Estado de Goiás (ESUMP) 6 . Os seus argumentos se repetem nos eventos dos quais participa, sempre voltados ao empresariado. Neles, o ministro se esforça para mostrar como a reforma é importante para as atividades econômicas, principalmente em seus aspectos que buscam evitar conflitos judiciais, bem como por normatizar novas formas de contratação, como a terceirização e o teletrabalho. Além disso, procura minimizar os argumentos dos juristas que entendem que a reforma é inconstitucional.

Em sua fala, o ministro defende que existe uma postura por parte de magistrados do trabalho em forçar a empresa a contratar diretamente. Afirma que foi contrário à tese de que call center seja atividade-fim de telecomunicações, o que, à época da discussão jurisprudencial, impediria a licitude da terceirização dessas atividades, e reforça sua defesa apontando que o STF confirmou a impossibilidade da limitação da terceirização ${ }^{7}$. Constantemente reitera a necessidade da Corte manter-se contida, não criando inovações por decisão judicial, seja no campo econômico, seja no campo social. O mesmo valendo para as outras instâncias, pois, segundo ele, em matéria do direito do trabalho, o princípio da dignidade humana não tem densidade normativa, não havendo uma definição clara do que seja; desse modo, o juiz não pode usá-lo como argumento para criar obrigações econômicas. Com isso, a reforma trabalhista surgiria para barrar exageros da Justiça do Trabalho. 
Sobre o tema da negociação coletiva, o Ministro sustenta que a jurisprudência sempre vê o empresário com uma conduta de má-fé e o trabalhador como ignorante. Defende que os princípios da proteção e da subsidiariedade devem ser conjugados, de modo que a intervenção do Estado deve ser subsidiária à atuação da família, escola, igrejas, empresas e dos sindicatos, nos casos em que persistir a vulnerabilidade. Analisa que, sendo a maior parte das regras trabalhistas consideradas indisponíveis, isso reduziria o papel da negociação. No entanto, interpreta que a Constituição já permite a redução salarial e de jornada via negociação coletiva, o que abriria possibilidades para negociações redutoras de direitos.

Segundo o ministro, essas possibilidades teriam sido consolidadas por meio do artigo 611-A da CLT, introduzido pela reforma trabalhista, com a prevalência do negociado sobre o legislado nos itens nele elencados ${ }^{8}$. Assim, ele afasta a interpretação que juristas fazem no sentido da vedação do retrocesso social, a partir do artigo $7^{\circ}$ da Constituição Federal ${ }^{9}$. Para tanto, utiliza-se de caso hipotético, sem qualquer base concreta na realidade social, ao criticar a interpretação de que a negociação coletiva só existe para aumentar direitos, como a feita pelos juristas que apontam o retrocesso social da reforma, pois poderia chegar a se adotar salários de 50 mil para 5 horas de trabalho, o que as empresas não aguentariam.

Outro tema destacado é o das relações nas plataformas digitais. Segundo o ministro, quando acionamos o celular, o fazemos para conseguir alguém que preste o trabalho. Com isso, ele desvincula a discussão da inserção desse trabalhador na organização econômica de uma empresa de transporte, que controla esse trabalhador e o mercado de trabalho em questão, via algoritmos. Para ele, se essas pessoas forem reconhecidas como empregados, nenhuma empresa terá interesse em assumir o risco dessa atividade. Com isso, sem maiores considerações sobre essas relações, manifesta-se contrariamente ao estabelecimento do vínculo empregatício em empresas como a Uber ${ }^{10}$.

Para analisar esses recursos retóricos, retomamos os escritos de Hirschman (1991). Assim, a "tese da perversidade", tratada pelo autor, argumenta que a introdução de novos direitos tende a produzir efeitos opostos aos desejados. Desde o processo constituinte de 1988, é recorrente que as vozes conservadoras utilizem esse recurso para afirmar que direitos sociais comprometem o emprego.

No caso das reformas propostas no Brasil, tal tese se apresenta sob a forma da defesa de contratos que retiram direitos conquistados e implicam em livre rotatividade da mão-de-obra, descaracterizando a identidade profissional do trabalhador e afastando-o dos sindicatos mais combativos. A ampliação da terceirização, bem como a adoção de formas de resolução do conflito sem participação das instituições públicas, ou ainda os processos de negociação sem respeito a direitos básicos ou diminuidores de um efetivo papel dos sindicatos, cumpririam esse papel fragmentador e desarticulador do coletivo trabalhador.

Outro recurso retórico, também lesivo ao movimento de ampliação da cidadania, dado que celebra a manutenção do status quo, é a "tese da futilidade", que segundo Hirschman (1991), sustenta que quaisquer mudanças serão ineficazes por deixarem intocadas estruturas da realidade. É nesse sentido, que as vozes reiteradamente afirmam que não adianta ampliar direitos se a maioria dos trabalhadores não tem contratos formais. Entende-se que, hoje, essas vozes passaram à ação para garantir que a tese da futilidade se realize nas instituições. 
Por fim, ainda segundo o mesmo autor, a "tese da ameaça" desestimula novas reformas progressistas, na medida que reitera que os custos comprometem conquistas prévias. Assim, um exemplo da tese da ameaça é a ideia de que pode perder-se a governabilidade se mais direitos sociais forem conquistados. Na linha neoliberal de "mais mercado e menos Estado", propõe-se a prevalência do negociado sobre o legislado e isso sem uma reforma sindical adequada, em um cenário possível de terceirização ampla e de deslegitimação das instituições públicas do trabalho.

O discurso aqui apresentado não se esforça em ter base empírica, desdenha os juízes que se baseiam na Constituição e no viés protetivo do trabalho, e, embora afirme priorizar a sociedade, na realidade, parte da sua importância para construir uma regulação privada, não sujeita a concepções públicas do direito e da política.

\section{O conservadorismo liberal na interpretação das leis normatizadoras das relações do trabalho no Poder judiciário.}

Há que fazer constar, contudo, que as mudanças no mundo do trabalho trazidas com a reforma começaram antes do seu processo legislativo, como o uso de procedimentos judiciais junto ao STF, para contestar os avanços legislativos e as interpretações judiciais da Justiça do Trabalho que foram se constituindo no pósConstituinte (ARTUR, 2007, 2012; FREITAS, 2011, 2012).

Com isso, ao receber essas demandas, o STF constituiu-se como lócus jurisprudencial central na área trabalhista e uma instituição de referência para as estratégias dos atores do mundo do trabalho. Foi o que aconteceu com a terceirização que, mesmo antes de sua normatização pelo Legislativo, encontrou respaldo na Corte, sinalizando, portanto, positivamente para a mudança que viria, em seguida, pelo Congresso. Nos votos dos ministros Luís Roberto Barroso, Luiz Fux, Alexandre Moraes e Gilmar Mendes, na Arguição de Descumprimento de Preceito Fundamental (ADPF) $324^{11}$, evidencia-se o argumento da naturalização da adoção da ampla terceirização diante das transformações da organização produtiva e da necessidade de criação de empregos, num quadro de crise econômica.

O apoio do STF às pautas conservadoras é antigo, Koerner e Freitas (2013) apontam que as forças conservadoras já faziam uso estratégico dessa Corte para bloquear decisões indesejadas na Assembleia Nacional Constituinte (ANC), e em troca da manutenção da estrutura do Supremo na Constituição de 1988.

Atualmente, a maioria dos Ministros do STF defendem uma leitura da Constituição para a proteção do mercado, buscando justificar a atualidade do seu discurso por meio de uma análise economicista, de custos e benefícios, no sentido de que a licitude da terceirização pode gerar empregos, chegando a ignorar ou afastar os argumentos das pesquisas, da doutrina e mesmo dos votos vencidos, que apontam para a precarização do mercado de trabalho via terceirização, o que distancia-se, portanto, do valor social do trabalho, presente na Carta Cidadã ${ }^{12}$.

Nessa ADI, o voto do ministro Gilmar Mendes revela a continuidade do enquadramento liberalizante e do prolongamento do processo contra-constituinte, na justificativa da necessidade de criação de postos de trabalho, independentemente de sua qualidade, de modo a caracterizar o modelo constitucional de proteção do trabalho como não realizável:

Ou seja, aqui não se trata de optarmos entre um modelo de trabalho formal e um modelo de trabalho informal, mas entre um modelo com 
trabalho e outro sem trabalho; entre um modelo social utópico, como tão frequentemente nos alertou Roberto Campos, e um modelo em que os ganhos sociais são contextualizados com a realidade (STF. ADPF 324, relator ministro Roberto Barroso, acórdão de 30 de agosto de 2018)

Nesse ambiente, o STF é o locus de interpretação da reforma trabalhista, com várias ADIs pendentes de julgamento. Nesta Corte, quando a discussão é sobre a legislação trabalhista, são recorrentes os debates centrais sobre eficiência econômica e justiça na área trabalhista. Enquanto confederações empresariais se robustecem por concretizar a visão de que a Constituição não deve se realizar amplamente nas relações de trabalho, muitas vezes encontrando respaldo em visões como as acima descritas no voto do ministro Gilmar Mendes, entidades sindicais e associações de juristas, como a Associação Nacional dos Magistrados da Justiça do Trabalho (ANAMATRA) a Associação Nacional dos Procuradores do Trabalho (ANPT), se esforçam para mostrar a incompatibilidade das mudanças com a proteção trabalhista na Constituição e com os direitos humanos do trabalho (ARTUR, FREITAS, 2017).

Atualmente, tramitam no STF mais de quarenta ações questionando a constitucionalidade das alterações promovidas pela Lei 13.467/2017, que instituiu a Reforma Trabalhista. Exemplificando a argumentação exposta, o relator da ADI $5666 / 1^{13}$, que trata do tema do acesso à justiça, o Ministro Relator Luís Roberto Barroso, utilizando argumentos sobre eficiência da Justiça, entende que a melhor posição é a que facilite crescimento econômico e expansão do mercado do trabalho, pois são analisados os custos sociais relacionados com o excesso de litigiosidade.

Por outro lado, com uma visão mais protetiva, a Procuradoria Geral da República, ao ingressar com a referida ADI, fundamenta o direito ao acesso à justiça como um direito internacionalmente reconhecido como direito humano e, ademais, menciona o conceito de mínimo existencial que deve conferir sustentação à dignidade humana, bem como que o crédito trabalhista, de caráter alimentar, está incluso no mínimo existencial. O Ministro Edson Fachin, que entendeu pela integral e completa inconstitucionalidade das limitações impostas pela Reforma ao acesso à Justiça, igualmente menciona que há desrespeito ao conceito do mínimo existencial a exigência do pagamento das custas, honorários advocatícios e periciais pelos necessitados, dado que o crédito obtido nos processos dificilmente altera a condição de hipossuficiente do beneficiário da Justiça Gratuita.

Por sua vez, na visão do Ministro Relator, estão ausentes as violações trabalhistas e a necessidade de repará-las judicialmente, enfatizando o esvaziamento dos conflitos como forma de melhorar o ambiente de negócios e de realizar o serviço público judicial, a qualquer custo, mesmo ignorando as dificuldades dos cidadãos em serem ouvidos.

Com isso, tal posição compatibiliza-se com o discurso que Koerner, Inamoti e Barreira (2015) apontaram como institucionalizado na Reforma do Poder Judiciário: de que a racionalidade de eficiência administrativa e o compromisso com a efetividade social deveriam materializar-se com a entrega do "serviço" e a instituição da cultura do consenso, mesmo dentro de uma sociedade marcada pelas desigualdades e conflitos. Segundo os autores, essa concepção prevaleceu sobre propostas alternativas, nas quais o Judiciário era visto enquanto poder político, em suas relações com a participação cidadã e a pluralização dos julgadores, composto por outros juízes que não somente os togados, comprometidos com a efetivação dos direitos sociais em cooperação com agências estatais e organizações da sociedade civil. 
Essa sobreposição de discursos, dos vencedores na Reforma do Judiciário, que emendaram a Constituição Federal de 1988 , com os discursos ora analisados, de interpretação dos artigos da Reforma Trabalhista, apontando a eficiência do Poder Judiciário, direcionado para evitar conflitos trabalhistas e aprofundar a desregulação do mercado, mesmo que afastando direitos fundamentais, trata-se, na verdade, da recuperação do discurso conservador, revestido em bases economicistas.

A ADI 5794, sobre a inconstitucionalidade dos artigos que retiraram a obrigatoriedade da contribuição sindical e que submetem o desconto e o recolhimento dessa contribuição à autorização prévia e expressa dos trabalhadores, ajuizada pela Confederação Nacional dos Trabalhadores em Transporte Aquaviário e Aéreo, na Pesca e nos Portos (Conttmaf), em 10 de outubro de 2017, foi julgada improcedente, mesmo com o voto do relator, Ministro Edson Fachin, votando pela sua procedência.

A autora da ADI apontou que a alteração legislativa desrespeitaria direitos e garantias fundamentais dos empregados, vez que o sindicato tem dever legal de assistir a categoria juridicamente, e o não recolhimento das contribuições torna-se um impeditivo; além disso, há um evidente desrespeito às normas da Organização Internacional do Trabalho (OIT), que preconizam a participação de empregados e empregadores em alterações legislativas sociais, alegando também a consequência da precarização e retrocesso social diante da destruição imediata das possibilidades dos sindicatos exercerem suas funções sem terem recursos efetivos.

$O$ voto do Ministro Luís Roberto Barroso, seguido em suas ideias em outros votos, tratou da questão como sendo do confronto entre um modelo com amparo estatal de origem autoritária e paternalista, e outro modelo, com maior autonomia individual. Neste último, os sindicatos deveriam competir pela atenção dos clientes. Assim, ele se afasta da compreensão da importância do papel dos sindicatos para melhoria das condições de vida e da democracia, bem como da necessidade condições institucionais para que possam atuar nesse sentido. Embora afirme a importância da sociedade civil e dos movimentos sociais, destaca o papel da competição no mercado como princípio regulador dessas entidades, além de insistir em uma visão conservadora de que essas entidades querem apenas obter vantagens do Estado.

Neste quadro, a discussão sobre constitucionalidade das alterações promovidas pela Reforma Trabalhista, no STF, reverbera a disputa política de interesses de classe, inclusive a semântica, revestida do discurso jurídico em torno da segurança jurídica. Conforme apontou o Dossiê do CESIT (2017) a chamada "segurança jurídica", tem sido usada pelos defensores da Reforma Trabalhista no sentido de que ela é alcançada com o aumento do leque dos contratos atípicos, com a autonomia da vontade das partes, principalmente individualizando negociações e mitigando poder dos sindicatos, e com a diminuição da ingerência dos tribunais trabalhistas. Na realidade, contudo, conforme o referido dossiê, com tal discurso, o objetivo da reforma é eliminar os entraves da regulação pública do trabalho, criando um ambiente que, em nome de criar empregos, gera a expansão da precarização, da vulnerabilidade, da insegurança, da desproteção.

\section{Considerações finais}

Por meio do institucionalismo histórico, desenvolveu-se como o discurso conservador-liberal, em relação à normatização das relações do trabalho, apesar de estar latente desde a Constituinte, ganhou força e se acirrou sistematicamente nas instituições dos três poderes, promovendo a Reforma Trabalhista em 2017, com argumentos de garantia da segurança jurídica, destinada somente ao mercado, e 
continuando na divulgação de ideias de total ruptura com o viés protecionista do direito do trabalho.

Na Constituinte, o grupo defensor dos ideais conservadores-liberalizantes, formado principalmente pelo grande empresariado paulista e por constituintes mais à direito no espectro político, não conseguiu barrar a constitucionalização de inúmeros artigos constitucionais em prol ao trabalhador; entretanto, produziu um texto mais contido em relação alguns direitos e deixou marcas desses ideais, os quais, a cada janela de oportunidade política, vieram à tona com o objetivo de mitigar o arcabouço jurídico protetivo dos direitos dos trabalhadores, tornando-o mais flexível, e reforçando o discurso com viés da eficiência e segurança jurídica.

Se, no pacto realizado na Constituinte, o movimento sindical, através do DIAP, teve maiores ganhos na constitucionalização de um arcabouço protetivo de direitos do trabalho, comparativamente aos menores ganhos por parte do empresariado, ainda sim, já estavam presentes naquele momento os discursos de liberalização de mercado, como se viu nas discussões sobre o estabelecimento da jornada de 40 horas semanais.

Para a concretização do pacto constitucional firmado em 1988 são necessárias formas democráticas de participação comunitária, asseguradas por meio de institutos de participação jurídico-política da comunidade, como meio de garantir efetivamente os direitos fundamentais. Ocorre, entretanto, que nossa história constitucional, especificamente na área da normatização das relações de trabalho, é marcada pela pressão das ações de cunho conservador-liberal, as quais sempre buscaram oportunidade de alterar o pacto constitucional firmado na Constituição de 1988.

Em meados dos anos 90, começa a despontar com maior força o discurso conservador-liberal de flexibilização das leis trabalhistas para tornar o mercado brasileiro competitivo no contexto da economia globalizada. Alterações significativas são iniciadas como respostas, com alterações sobre contrato a prazo determinado, banco de horas, dentre outras. Embora nos governos de Luiz Inácio Lula da Silva tenha havido um arrefecimento na produção das leis flexibilizadoras, não houve maiores avanços em consensos para reforma sindical.

Com a crise do governo de Dilma Rousseff, abriu-se nova janela de oportunidade para o empresariado, a mídia e os bancos difundirem nas instituições a necessidade de profunda e radical reforma trabalhista, para desonerar a folha de pagamento e desburocratizar as normas trabalhistas. A bandeira da modernização e da necessidade da segurança jurídica, pró-mercado, é defendida como forma de aumentar a produtividade, os salários e os empregos.

A Reforma Trabalhista é aprovada, sem levar em consideração argumentos que não fossem do empresariado e dos bancos. O discurso conservador-liberal sai vitorioso na retirada de direitos dos trabalhadores, com a reformulação do conceito de trabalhador autônomo, a criação de contrato intermitente, a ampliação das possibilidades de negociação individual do empregado diretamente com o empregador, a prevalência do negociado sobre o legislado, mesmo que não fosse a norma mais favorável ao trabalhador, dentre outras alterações.

O atual governo de Jair Messias Bolsonaro, com o propósito de aprofundar ainda mais a desregulamentação das leis do trabalho, avançou na defesa de total ruptura com o protecionismo do direito do trabalho, criando o GAET, com membros defensores da visão conservadora-liberal, e sem representantes dos sindicatos dos trabalhadores. Em diferentes momentos, os membros participam de eventos promovidos por suas entidades empresariais, como CNI, e, em seus discursos, retomam os argumentos de segurança jurídica pró-mercado. 
Nesse contexto, o país tem vivenciado ataques ao núcleo de direitos fundamentais da Constituição. Por meio desses ataques, as posições pró-mercado estão conseguindo ganhos, principalmente com a ressignificação e o afastamento dos direitos constitucionais, dentro do Poder Judiciário, particularmente no STF, quando chamado a tratar dos avanços legislativos e das interpretações da Justiça do Trabalho.

Esses discursos conservadores e as decisões judiciais flexibilizantes concernentes ao mundo do trabalho merecem ser acompanhados por conformarem um ambiente institucional que prescinde dos comandos da Constituição em torno do valor social do trabalho e dos direitos fundamentais do trabalho. Com isso, impõem um mercado de trabalho desregulado e desprovido das categorias políticas e jurídicas de proteção trabalhista baseadas em princípios democráticos constitucionais

(Recebido para publicação em setembro de 2020)

(Reapresentado em setembro de 2020)

(Aprovado para publicação em dezembro de 2020)

\section{Cite este artigo}

ARTUR, Karen; FREITAS, Ligia Barros de, 2020. A extensão das ideias conservadoras-liberalizantes do processo constituinte por meio de juristas de trabalho: uma agenda de pesquisa. Revista Estudos Políticos: a publicação semestral do Laboratório de Estudos Hum(e)anos (UFF). Rio de Janeiro, Vol.11 | N.22, pp. 58-81, dezembro de 2020.

\section{Notas}

1. Conforme a Portaria 1.001, publicada em 04/09/2019 e republicada em 12/09/2019.

2. Embora as forças políticas conservadoras e seu pensamento tenham uma trajetória na cena política do país anterior à $A N C$, de rupturas e continuidades (CHABOUB, 2020; LINCH, 2017, 2020; BRANDÃO, 2007), no presente trabalho, a delimitação metodológica, do marco temporal inicial, é o momento da Constituinte.

3. SETUBAL, Roberto. A importância de reforma trabalhista. Folha de São Paulo, São Paulo, 01/07/2017. Disponível em: https://www1.folha.uol.com.br/paywall/login.shtml?ht tps://www1.folha.uol.com.br/opiniao/2017/07/189767 1-a-importancia-da-reforma-trabalhista.shtml. Acesso: 01 mar 2021. 
4. Confederação Nacional da Indústria (CNI). CNI realiza seminário para debater a modernização da legislação trabalhista. 09.10.2017. Disponível em: https://noticias. portaldaindustria.com.br/noticias/traba Iho/cni-realiza-seminario-para-debater-a-

modernizacao-da-legislacao-trabalhista/. Acesso em 10 out 2019. Para a fala do ministro Ives Gandra, neste seminário, ver 0 quinto painel: https://www.youtube.com/watch?v=PncL8nFSkaI\&t= $8 \mathrm{s.}$

5. A ausência de diálogo social, em desconformidade com as normas da OIT, tem sido criticada por esses atores, que estimularam a análise das violações da reforma trabalhista às convenções internacionais da OIT pela Comissão de Aplicação de Normas da OIT. Ver: ANAMATRA (2019).

6. Para acesso à programação, ver: MP-GO. http://www.mpgo.mp.br/portal/noticia/evento-esumpibsejur-seguranca-juridica\#.XrmqEWhKjIU. Para acesso à fala do ministro: ESUMP MPGO. I Congresso Brasileiro de Segurança Jurídica. Disponível em: https://www.youtube.com/watch?v=8DcG6wXGHPs\&t =6636s. Acesso em 11 mai 2020 .

7. Decisão no Recurso Extraordinário Recurso Extraordinário com Agravo (ARE) 791932, de 11 de outubro de 2018.

8. "Art. 611-A. A convenção coletiva e o acordo coletivo de trabalho têm prevalência sobre a lei quando, entre outros, dispuserem sobre (...)"

9. "Art.70. São direitos dos trabalhadores urbanos e rurais, além de outros que visem à melhoria de sua condição social (...)".

10. Essa visão contrasta com a atuação do Ministério Público do Trabalho, que formou um grupo para estudar as tendências de regulação em diversos países e que vem defendendo que plataformas como a Uber são empresas de transporte, não meras intermediadoras de serviços. Com isso, o objetivo dessas plataformas é fugir da regulação trabalhista (Oitaven; Carelli; Casagrande, 2018).

11. STF. ADPF 324, relator ministro Roberto Barroso, acórdão de 30 de agosto de 2018. 
12. O presente trabalho concorda com Paixão (2020) que menciona que, atualmente, os votos divergentes, que respeitam a constitucionalização dos direitos trabalhista, portanto, com visão mais protetiva ao trabalhador, restringem-se aos da Ministra Rosa Weber e dos Ministros Edson Fachin e Ricardo Lewandowski.

13. A ADI 5666, proposta pela Procuradoria Geral da República (PGR), em 28 de agosto de 2017, com pedido liminar, questiona a extensão da Justiça Gratuita, mitigada pela Reforma, pois não isenta ao pagamento das custas, honorários sucumbenciais e periciais aos beneficiários que venha obter créditos no processo em que foi condenado as referidas despesas, ou em outro processo.

\section{Referências bibliográficas}

ARTUR, Karen. O TST frente à terceirização. São Carlos: EdufsCar/Fapesp, 2007.

ARTUR, Karen. O novo poder normatizador do TST: dissídios individuais e atores coletivos. São Paulo: LTr, 2012.

ARTUR, Karen; FREITAS. Ligia Barros de. Direitos do trabalho em disputa no STF: o papel dos procuradores do trabalho. Revista Debates, Porto Alegre, v. 11, n. 3, 2017, p. 101-126.

ARTUR, Karen, GRILLO, Sayonara.Terceirização e arenas de reconfiguração do Direito do Trabalho no Brasil. Revista de Estudos Institucionais, v. 6, n. 3, set./dez. 2020 p. 1184-1213.

ASSOCIAÇÃO NACIONAL DOS MAGISTRADOS DA JUSTIÇA DO TRABALHO (ANAMATRA). Reforma trabalhista: OIT decide que Brasil permanece sendo monitorado por violação à Convenção 98. Brasília, 19 de junho de 2019. Disponível em: https://www.anamatra.org.br/imprensa/noticias/2831 8-reforma-trabalhista-oit-decide-que-brasilpermanece-sendo-monitorado-por-violacao-aconvencao-98. Acesso em 27 de abr 2020.

BALTAR, Paulo Eduardo de Andrade et al. Trabalho no governo Lula: uma reflexão sobre a recente experiência brasileira. [s.l.]: 2010. Disponível em https://www.global-labour- 
university.org/fileadmin/GLU_Working_Papers/GLU_ WP_No._9_portuguese.pdf Acesso em: 07 jun. 2020.

BASTOS, Marcus Vinícius Fernandes. Comissão Afonso Arinos, Assembleia Nacional Constituinte e a elaboração da Constituição de 1988: construção, procedimento e legitimidade. 2018. Dissertação (Mestrado em Direito)—Universidade de Brasília, Brasília, 2018.

BRANDÃO, Gildo Marçal. Linhagens do pensamento político brasileiro. São Paulo: Editora HUCITEC, 2007

CARDOSO, Adalberto. À beira do abismo: Uma sociologia política do bolsonarismo. 1 ed. Rio de Janeiro: Amazon, 2020. E-book Kindle.

CHALOUB, Jorge. América Latina como outro: um discurso da direita brasileira. AP Agenda Política. Volume 8, Número 1, São Carlos, 2020, p. 157-201.

CENTRO DE ESTUDOS SINDICAIS E ECONOMIA DO TRABALHO (CESIT). Dossiê Reforma trabalhista. Disponível em: http://www.cesit.net.br/dossiereforma-trabalhista/ Campinas: Unicamp, 2017. Acesso em:. 07 jun. 2019.

CONFEDERAÇÃO NACIONAL DA INDÚSTRIA (CNI). CNI realiza seminário para debater a modernização da legislação trabalhista. 09.10.2017. Disponível em: https://noticias.portaldaindustria.com.br/noticias/trab alho/cni-realiza-seminario-para-debater-amodernizacao-da-legislacao-trabalhista/. Acesso em 10 outubro de 2019.

CITTADINO, Gisele. Pluralismo, direito e justiça distributiva. Elementos da filosofia constitucional contemporânea. Rio de Janeiro. Lumen Juris, 1999.

CITTADINO, Gisele. Judicialização da Política. Constitucionalismo Democrático e Separação de Poderes. In: VIANNA, Luiz Werneck (Org). A Democracia e os Três Poderes no Brasil. Belo Horizonte, Editora UFMG, Rio de Janeiro IUPERJ/FAPERJ, 2002, p.17-42.

COSTA, Tarcísio. O debate constituinte: uma linguagem democrática?. Lua Nova, São Paulo, 88, 2013, p. 89-140. 
DINIZ, Simone; NORONHA, Lincoln. Direitos Trabalhistas e Sindicais: O Conservadorismo da Constituição de 1988 e das Tentativas de Reforma nos Anos 90. In: PRAÇA, Sérgio; DINIZ, Simone. (Org.). Vinte Anos de Constituição. São Paulo: Paulus, 2008, p. 139-159.

ESUMP MPGO. I Congresso Brasileiro de Segurança Jurídica. Disponível em: https://www.youtube.com/watch?v=8DcG6wXGHPs\& $\mathrm{t}=6636 \mathrm{~s}$. Acesso em 11 mai 2020.

FREITAS, Lígia Barros de. A política e o TST na Constituição dos Direitos do Trabalho. São Paulo: LTr, 2011.

FREITAS, Lígia Barros de. A consolidação constitucional do TST na longa constituinte (19872004). Tese (Doutorado em Ciência Política)Programa de Pós-Graduação em Ciência Política, Universidade Federal de São Carlos, São Carlos, 2012.

HALL, Peter A. and TAYLOR, Rosemary C. R. As três versões do neo-institucionalismo. Lua Nova [online]. 2003, n.58, p.193-223.

HIRSCHMAN, Albert $O$. The rhetoric of reaction: perversity, futility, jeopardy. Cambridge, MA:HUP, 1991.

KREIN, José Dari; OLIVEIRA, Marco Antonio. Mudanças institucionais e relações de Trabalho: as iniciativas do governo FHC no período de 1995-1998. Revista do TRT da 150 Região, n. 22, 2003.

KREIN, José Dari; OLIVEIRA, Roberto Véras; FILGUEIRAS, Vitor Araújo (orgs.) Reforma trabalhista no Brasil: promesssas e realidade. Campinas: REMIR/Curt Nimuendajú, 2019.

KOERNER, Andrei e FREITAS, Lígia Barros de. O Supremo na Constituinte e a Constituinte no Supremo. Lua Nova, 88, 2013, p. 141-184.

KOERNER, Andrei. Ativismo Judicial? Jurisprudência constitucional e política no STF pós-88. Novos Estudos.96, julho 2013, p.69-85. 
KOERNER, Andrei; INATOMI, Celly Cook; BARREIRA, Karen Sakalauska. Dez anos de racionalização da gestão judicial no Brasil: efeitos e perspectivas. Revista Direito \& Praxis, vol 07, n.12, 2015, p. 236-364.

LYNCH, Christian Edward Cyril. Conservadorismo Caleidoscópico: Edmund Burke e o Pensamento Político do Brasil Oitocentista. Lua Nova, São Paulo, n. 100 , janeiro 2017, p. 313-362.

LYNCH, Christian Edward Cyril. A utopia reacionária do governo Bolsonaro (2018-2020). Insight Inteligencia. Ano XXII, N. 89, abril/ maio de 2020, p. 21-40. Disponível em: https://insightinteligencia.com.br/a-utopiareacionaria-do-governo-bolsonaro-2018-2020/. Acesso em 20 fev 2021.

MARGATO, Rodolfo; MOLAN, Maurício. Reforma Trabalhista: Informalidade e Insegurança Jurídica. Santander. 14 de junho de 2017. Disponível em: https://cms.santander.com.br/sites/WPS/documentos /arq-estudos-macro-junho-2017_v2/19-0123_120725_arq-estudos-macro-junho-2017.pdf. Acesso em 10 mar 2021.

NORONHA, Eduardo Garuti. Entre a lei e a arbitrariedade: mercados e relações de trabalho no Brasil. São Paulo: LTR, 2000.

NORONHA, Eduardo Garuti; DE NEGRI, Fernanda., ARTUR, Karen. Custos do trabalho, direitos sociais e competitividade industrial. In: DE NEGRI, J. A., DE NEGRI, F., COELHO, D. (orgs.). Tecnologia, exportação e emprego. Brasília: Ipea, 2006, p. 161201.

OITAVEN, Juliana Carreiro Corbal; Carelli, Rodrigo de Lacerda; Casagrande, Cássio Luís. Empresas de transporte, plataformas digitais e a relação de emprego: um estudo do trabalho subordinado sob aplicativos. Brasília: Ministério Público do Trabalho, 2018.

PESSANHA, Elina Gonçalves da Fonte. O papel da Justiça do Trabalho na garantia de direitos e igualdade: breve balanço nos 20 anos da Constituição de 88. In: KREIN, José Dari; SANTANA, Marco Aurélio; BIAVASCHI, Magda Barros. Vinte anos da 
Constituição Cidadã no Brasil, São Paulo: LTr, 2010, p. 128-143.

ROTHSTEIN, Bo. Political Institutions: an Overview. In: R. E. Goodin e Hans-Dieter. Klingemann (Ed). A New Handbook of Political Science. New York. Oxford University Press, 1998. Political Institutions: An Overview, p. 133-166

SANTOS, Wanderley Guilherme dos. Regresso. Máscaras institucionais do liberalismo oligárquico. Rio de Janeiro, Opera Nostra Editora, 1994.

SALGADO, Eneida Desiree. Tijolo por tijolo em um desenho (quase) lógico: vinte anos de construção do projeto democrático brasileiro. Dissertação de Mestrado em Direito do Estado, Setor de Ciências Jurídicas, Universidade Federal do Paraná, 2005.

SETUBAL, Roberto. A importância de reforma trabalhista. Folha de São Paulo, São Paulo, 01/07/2017. Disponível em: https://www1.folha.uol.com.br/paywall/login.shtml?ht tps://www1.folha.uol.com.br/opiniao/2017/07/18976 71-a-importancia-da-reforma-trabalhista.shtml. Acesso: 01 mar 2021.

SILVA, Sayonara Grillo Coutinho Leonardo da. Relações coletivas de trabalho: configurações insittucionais no Brasil contemporâneo. São Paulo: Ltr, 2008.

OLIVEIRA, Roberto Véras de. Das greves do $A B C$ ao conselho de relações de trabalho: chances e limites da ação sindical institucional. Lua Nova, São Paulo, 104, 2018, p. 97-131.

PAIXÃO, Cristiano. 30 anos: Crise e Futuro da Constituição de 1988. ANPT, 04 de maio de 2018. Disponível em: http://www.anpt.org.br/imprensa/26anpt/artigos/3311-30-anos-crise-e-futuro-daconstituicao-de-1988. Acesso em 01 jun 2020.

WEBINAR Clínica do Direito do Trabalho da UFPR: O STF e a MP 936: análise da ADI 6363. Apresentado por José Dari Krein, Cristiano Paixão, Sidnei Machado e Miguel Godoi. Curitiba, Clínica do Direito do Trabalho da UFPR, 12 de jun 2020. Vídeo (1h43m12s). Publicado pela Clínica do Direito do Trabalho da UFPR. Disponível em: 
https://www.youtube.com/watch?v=XqsgTWY7_U\&f eature=youtu.be. Acesso em 13 jun 2020.

VIANNA, Luiz W; CARVALHO, Maria A. R. de; MELO, Manuel P. C.; BURGOS, Marcelo B. A judicialização da política e das relações sociais no Brasil. Rio de Janeiro: Revan, 1999.

VIANNA, Luiz Werneck; BURGOS, Marcelo. Revolução Processual do Direito e Democracia Progressiva.In: VIANNA, Luiz Werneck (Org). A Democracia e os Três Poderes no Brasil. Belo Horizonte, Editora UFMG, Rio de Janeiro IUPERJ/FAPERJ, 2002, p.337-491. 